Article

\title{
Symmetrical and Asymmetrical Rectifications Employed for Deeper Ocean Extrapolations of In Situ CTD Data and Subsequent Sound Speed Profiles
}

\author{
Kashif Iqbal ${ }^{1,2}$, Minghui Zhang ${ }^{1,2, *}$ and Shengchun Piao ${ }^{1,2}$ \\ 1 Acoustic Science and Technology Laboratory, Harbin Engineering University, Harbin 150001, China; \\ kashifjamshed607@hrbeu.edu.cn (K.I.); piaoshengchun@hrbeu.edu.cn (S.P.) \\ 2 College of Underwater Acoustic Engineering, Harbin Engineering University, Harbin 150001, China \\ * Correspondence: zhangminghui@hrbeu.edu.cn
}

Received: 15 July 2020; Accepted: 2 September 2020; Published: 4 September 2020

\begin{abstract}
The multinational Argo program, which was initiated in 1999, has completed its global requirement of 3000 floats deployed by 2007. This program has revolutionized ocean observations with the provision of varying data in the upper half of the ocean. However, various studies have reiterated the requirement for deep ocean coverage, since the ocean below 2000 meters $(\mathrm{m})$ is warming. In this regard, full-depth studies are mandatory in order to estimate the rising sea level due to thermal expansion and analyze critical parameters of deep ocean circulation sub $2000 \mathrm{~m}$; further, data below $2000 \mathrm{~m}$ are mandatory for multifarious model simulations. As a landmark initiative, in mid-2015, the "Deep Argo Implementation Workshop" was held in Hobart. An array comprising 1228 floats was suggested by G. C. Johnson, rendering coverage of $5^{\circ}$ latitude $\times 5^{\circ}$ longitude $\times 15$-day cycles. This was conclusively agreed to be an affordable solution for varying scientific needs for assessing data in abyssal oceans. Thence, Deep New profillNg float of JApan (NINJA) and Deep Arvor floats were developed by Japan and France, respectively, to cover depths of 0-4000 m. Similarly, Deep Autonomous Profiling Explorer (APEX) and Deep Sounding Oceanographic Lagrangian Observer (SOLO) by the United States were designed to cover 0-6000 $\mathrm{m}$. The data offered by this underdeveloped deep pilot array are scarce on both temporal and spatial scales. This particular study offers an ingenious and novel approach to extrapolating conductivity-temperature-depth (CTD) profiles, as well as sound speed profiles (SSPs), in abyssal oceans below $2000 \mathrm{~m}$. The primitive results of this method exhibited certain discrepancies which were subsequently rectified by modifying the aforementioned method both symmetrically and asymmetrically in an innovative way. The final outcomes of this method are almost identical to the in situ values obtained from Deep Argo floats, and in this way, offer a way to compute deep ocean calculations both spatially and temporally since Deep Argo floats are aimed at relatively sparse deployments and require a longer duration to provide data ( $5^{\circ}$ latitude $\times 5^{\circ}$ longitude $\times 15$-day cycles) as compared to Core Argo data ( $3^{\circ}$ latitude $\times 3^{\circ}$ longitude $\times 10$-day cycles). The SSP computations were conducted by employing multiple equations such as Chen and Millero, Del Grosso, and UNESCO (United Nations Educational, Scientific, and Cultural Organization) algorithms. The study concludes by offering transmission loss rectifications by employing the aforementioned method as a future course of action.
\end{abstract}

Keywords: Deep Argo floats; extrapolations; in situ CTD data; sound speed profile computations

\section{Introduction}

The international Argo program, which was initiated in 1999, began deployments of floats globally and achieved its landmark success of 3000 floats by the year 2007. The in situ data of around $2000 \mathrm{~m}$ 
depths from such floats are available online free of charge. The program has enabled the scientific community to monitor the upper half of the ocean in near real time. The initial measurements included in situ vertical profiles of salinities and temperatures along the depths of global oceans. The employment of Argo data encompasses research in oceanography, climatological analysis, academic activities, pragmatic data assimilation in the ocean, and, finally, seasonal to decadal predictions on both broad temporal and spatial scales, which makes Argo a core integrant of various projects such as the World Climate Research Program (WCRP)/Climate Variability and Predictability (CLIVAR) [1-3]. The accomplishment of such successful milestones has compelled Argo to expand in terms of vertical depth, to incorporate multifarious sensors, and to extend the observatory regions, such as western borderline currents, across the equator. The available deep ocean dataset mainly comprises a couple of sources. One is sporadic hydrographic segments repeated on a decadal basis by employing oceanographic vessels analogous to that used during the World Ocean Circulation Experiment (WOCE) during the 1900s. The other is the current Global Ocean Ship-Based Hydrographic Investigations Program (GO-SHIP). The employment of such historical datasets in multiple studies has illustrated that patterns of both mass and thermal transportation in the deeper ocean are critical components of the worldwide circulation and its relevant exchange with the atmosphere. In this regard, to analyze more accurate regional budgets, superior temporal resolutions are desired in the deeper ocean globally. Eventually, a Deep Argo array covering the world's oceans may guide accurate observations regarding the climate system [4-8]. Recently, in order to improve on the Core Argo program, Biogeochemical Argo (BGC-Argo) and Deep Argo were included to measure not only the multifarious properties of oceans but to dive deeper into the oceans to observe the remaining half of the volume of global oceans [9]. Such deeper observations suggest that heat accumulation by the world's oceans was at a rate of $33 \pm 21$ TW from 1991 to 2010. Predictions based on warming between 2000-4000 m specifically in the Southern Ocean offer an estimate for global warming at this particular depth to be over $66 \%$ of the aforementioned heat accumulation rate. Similarly, surveillance beneath $4000 \mathrm{~m}$ illustrates a huge southerly gradient in the deeper heat accumulation rate. Moreover, far southern basins are accumulating heat 10 times faster than their deep counterpart basins on the northern side. As mentioned earlier, such studies are based on uncertainties which make the deployment of the Deep Argo array mandatory. In this context, the Deep Argo program was already launched in mid-2015 when the Deep Argo Implementation Workshop was held in Hobart, Australia. Subsequent to this, a second international Deep Argo Workshop was conducted at the Commonwealth Scientific and Industrial Research Organization (CSIRO) in Hobart, Tasmania, Australia during 13-15 May, 2019. Thence, four types of Deep Argo floats were deployed, mostly in zonal pilot arrays near the southwest Pacific basin, the South Australian and Australian Antarctic Basins, and the North Atlantic. In such areas, Deep Arvor (France) and Deep New Profiling Float of Japan (NINJA), employing Sea-Bird Electronics, Inc. (SBE) SBE-41 conductivity-temperature-depth (CTD) by Sea-Bird, are capable of covering depths of $4000 \mathrm{~m}$. Similarly, Deep SOLO and Deep APEX, equipped with SBE-61 CTD, offer ocean coverage up to $6000 \mathrm{~m}$. By July 2019, 80 such Deep Argo floats were active and being pursued by the World Meteorological Organization and Marine Meteorology in situ Observing Programmes Support Centre (WMO-IOC's JCOMMOPS). Out of these 80 floats, 47 were Scripps Deep SOLO, 8 were Deep SOLOs which were commercially manufactured (MRV), 20 were Deep Arvors, 3 were Deep APEXs, and 2 were Deep NINJAs. The complete range of Deep Argo floats is capable of providing near-real-time (NRT) pressure, temperature, and salinity measurements while the float is ascending from a programmed depth to the surface [10-13]. In order to offer wider coverage of deep ocean monitoring, both temporally and spatially, this particular study employs an ingenious method based on the least squares method [14] for first-order implementation to extrapolate vertical profiles of certain CTD parameters along with the subsequent sound speed profiles (SSPs) computed by multiple equations. The discrepancies in the outcomes of the basic first order are rectified innovatively by improved second order as well as by conducting symmetrical and asymmetrical rectifications in order to bring extrapolations almost identical to the measured in situ values of the relative Argo floats. The inputs for the aforementioned 
method are in situ data from Deep Argo floats for the sake of extrapolation which takes course below $2000 \mathrm{~m}$ until the end of the available data. The study proceeds by conducting experimentation on varying cycles of a Deep Argo float to offer wider spatiotemporal coverage, since Deep Argo floats are aimed at sparse deployments ( $5^{\circ}$ latitude $\times 5^{\circ}$ longitude $\times 15$-day cycles) in comparison to Core Argo data $\left(3^{\circ}\right.$ latitude $\times 3^{\circ}$ longitude $\times 10$-day cycles) $[13,15]$. Furthermore, symmetric and asymmetric extrapolations are applied on three Argo floats to illustrate the outcomes of extrapolation which are analogous to in situ values of floats. Similarly, the study concludes with transmission loss rectifications based on these outcomes as a future course of action. The SSPs for this study are computed using three equations, i.e., the Chen and Millero equation (1977) [16], the UNESCO (United Nations Educational, Scientific, and Cultural Organization) equation [17,18], and the Del Grosso equation (1974) $[17,18]$. The method shows promise in offering wider spatiotemporal coverage with the help of the most appropriate extrapolated values by employing Deep Argo as well as Core Argo floats' in situ data. In this way, the deeper oceans are measured more accurately on both temporal and spatial scales. The method initially relies on Deep Argo floats in the proximity and can then be employed for any time and almost any place, depending solely on the presence of conventional Core Argo floats with profiling depths of $2000 \mathrm{~m}$ in that particular locality for subsequent symmetric and/or asymmetric (whichever generates accurate values) extrapolations to the depths based on the particular Deep Argo float.

\section{Materials and Methods}

\subsection{The Proposed Extrapolation Methodology}

The aforementioned method to rectify erroneous extrapolated values is presented mathematically in this particular section. This proposed method is based on the least squares method [14]. The data are presented in Equation (1) below, where $x$ represents the salinities, temperatures, and SSPs in psu, ${ }^{\circ} \mathrm{C}$, and $\mathrm{m} / \mathrm{s}$, respectively. Similarly, y represents the depth in meters, and $i=1,2,3, \ldots, n$.

$$
D=\left(x_{i}, y_{i}\right)
$$

Employing polynomials for curve fitting, we have

$$
f(x)=\sum_{j=0}^{m} k_{j} x^{j}
$$

The desired design parameters are $k=\left(k_{0}, k_{1}, \ldots, k_{m}\right)$. Then, we have

$$
R(k)=\sum_{i=1}^{n}\left[y_{i}-f\left(x_{i}\right)\right]^{2} .
$$

The classical least square fitting for the most appropriate fitting is applied [19]. By taking the differential on both sides, we have

$$
\frac{\partial R(\kappa)}{\partial k_{j}}=-2 \sum_{i=1}^{n}\left[y_{i}-f\left(x_{i}\right)\right] x_{i}^{j}=0, j=0 \ldots m .
$$

By substituting Equation (2) into Equation (4), we have

$$
\sum_{i=1}^{n} \sum_{l-0}^{m} k_{l} x_{i}^{l+j}=\sum_{i=1}^{n} y_{i} x_{i}^{j}
$$

which is of the form

$$
A \kappa^{*}=b
$$

where $A=\left\{a_{i j}\right\}$ with $a_{i j}=\sum_{l=0}^{m} x_{i}^{l+j}$ and $b=\left\{b_{j}\right\}$ with $b_{j}=\left\{\sum_{i=1}^{n} y_{i} x_{i}^{j}\right\}, j=0, \ldots, m$ and $i=1, \ldots, n$.

The values $m$ and $n$ are free, and a particular range is set for them in order to obtain extrapolations for the salinities, temperatures, and SSPs which are almost identical to the in situ values of the Deep 
Argo floats. Initially, $m$ was set to 1 for extrapolations against varying values of $n$ which are mentioned in the ensuing results section, and the resulting first-order extrapolation presented anomalies relative to the in situ values of Argo floats. Then, $m$ was set to 2, and the outcomes were improved with this second-order implementation. This activity was conducted for three Deep Argo floats of $4000 \mathrm{~m}$, as well as on a couple of floats with profiling capability of $6000 \mathrm{~m}$ depth; the results are graphically presented in Sections 3.1 and 3.2, respectively. Furthermore, a couple of activities were conducted as detailed in Section 3.3 by employing extrapolations on three Deep Argo floats offering data up to depths of $\sim 5000 \mathrm{~m}$ in the Pacific Ocean. One such activity dealt with the illustration of wider spatiotemporal coverage by conducting extrapolations on multiple cycles of one of these three floats. Similarly, the SSPs for these three floats were computed and extrapolated to exhibit the improved extrapolations asymmetrically as compared to the symmetrical ones. This was done by manipulating the ranges of both $m$ and $n$.

The in situ vertical profiles of salinity, temperature, and subsequent SSPs employed for this entire activity are available online [20]. The database offers Argo floats for the Atlantic, Indian, and Pacific Oceans by searching any of them using the World Meteorological Organization identification (WMO ID) number. After selection, the website offers multifarious details regarding that particular float. The desired vertical profiles are available both in Netcdf and Ascii formats. The sound speed profiles were computed by employing the vertical profiles of salinity, temperature, and pressure obtained from these data using the equations below:

- $\quad$ The Chen and Millero Equation (1977) [16];

- $\quad$ The UNESCO Equation [17,18]; and

- $\quad$ The Del Grosso Equation (1974) [17,18].

These equations are discussed in the ensuing Section 2.2.

\subsection{Sound Speed Profile (SSP) Computations}

The sound speed computations for this study were conducted by employing three equations: the Chen and Millero (1977) [16], Del Grosso (1974) [17,18], and UNESCO (United Nations Educational, Scientific, \& Cultural Organization) algorithms $[17,18]$. In this study, we compared the extrapolations for all of these equations; the Del Grosso equation $[17,18]$ was employed for the improved extrapolated rectifications, as will be illustrated in the figures of ensuing sections.

\subsubsection{SSP Computations Using the Chen and Millero Equation (1977)}

This sound speed equation was numerically computed for specimens of seawater, which were either diluted by employing pure water or concentrated with the help of evaporation by Millero and Chen in 1977 [16], and it is given as follows.

$$
\begin{aligned}
& U(S, t, p)=C_{w}(t, p)+A(t, p) S+B(t, p) S^{3 / 2}+D(t, p) S^{2} \\
& C_{w}(t, p)=C_{00}+C_{01} t+C_{02} t^{2}+C_{03} t^{3}+C_{04} t^{4}+C_{05} t^{5} \\
& +\left(C_{10}+C_{11} t+C_{12} t^{2}+C_{13} t^{3}+C_{14} t^{4}\right) p \\
& +\left(C_{20}+C_{21} t+C_{22} t^{2}+C_{23} t^{3}+C_{24} t^{4}\right) p^{2} \\
& +\left(C_{30}+C_{31} t+C_{32} t^{2}\right) p^{3} \\
& C_{00}=+1402.388 \quad C_{10}=+0.153563 \\
& C_{01}=+5.03711 \quad C_{11}=+6.8982 E-4 \\
& C_{02}=-5.80852 E-2 \quad C_{12}=-8.1788 E-6 \\
& C_{03}=+3.3420 E-4 \quad C_{13}=+1.3621 E-7 \\
& C_{04}=-1.47800 E-6 \quad C_{14}=-6.1185 E-10
\end{aligned}
$$




$$
C_{05}=+3.1464 E-9
$$

$$
\begin{aligned}
& C_{20}=+3.1260 E-5 \\
& C_{30}=-9.7729 E-9 \\
& C_{21}=-1.7107 \\
& C_{31}=+3.8504 E-10 \\
& C_{22}=+2.5974 E-8 \\
& C_{32}=-2.3643 E-10 \\
& C_{23}=-2.5335 E-10 \\
& C_{32}=-2.3643 E-12 \\
& C_{23}=-2.5335 E-10 \\
& C_{24}=+1.0405 E-12 \\
& A(t, p)=A_{00}+A_{01} t+A_{02} t^{2}+A_{03} t^{3}+A_{04} t^{4} \\
& +\left(A_{10}+A_{11} t+A_{12} t^{2}+A_{13} t^{3}+A_{14} t^{4}\right) p \\
& +\left(A_{20}+A_{21} t+A_{22} t^{2}+A_{23} t^{3}\right) p^{2} \\
& +\left(A_{30}+A_{31} t+A_{32} t^{2}\right) p^{3} \\
& A_{00}=+1.389 \\
& A_{10}=+9.4742 E-5 \\
& A_{01}=-1.262 E-2 \\
& A_{11}=-1.2580 E-5 \\
& A_{02}=+7.164 E-5 \\
& A_{12}=-6.4885 E-8 \\
& A_{03}=+2.006 E-6 \\
& A_{13}=+1.0507 E-8 \\
& A_{04}=-3.21 E-8 \\
& A_{14}=-2.0122 E-10 \\
& A_{20}=-3.9064 E-7 \\
& A_{30}=+1.100 E-10 \\
& A_{21}=+9.1041 E-9 \\
& A_{31}=+6.649 E-12 \\
& A_{22}=-1.6002 E-10 \\
& A_{32}=-3.389 E-13 \\
& A_{23}=+7.988 \\
& \text { E-12 } \\
& B(t, p)=B_{00}+B_{01} t+\left(B_{10}+B_{11} t\right) p \\
& B_{00}=-1.922 \quad E-2 \\
& B_{10}=+7.3637 E-5 \\
& B_{01}=-4.42 \quad E-5 \\
& B_{11}=+1.7945 E-7 \\
& D(t, p)=D_{00}+D_{10} p \\
& D_{00}=+1.727 \quad E-3 \\
& D_{10}=-7.9836 E-6
\end{aligned}
$$

The range of validity appears to be $S=0$ to $40, t=0$ to $40{ }^{\circ} \mathrm{C}, p=0$ to 1000 decibars; the standard deviation is $0.19 \mathrm{~m} / \mathrm{s}$.

\subsubsection{SSP Computations Using the UNESCO Algorithm}

The UNESCO equation, also called the UNESCO equation: Chen and Millero, is based on Chen and Millero (1977) [17]. The original UNESCO paper was presented in a 1983 publication by Fofonoff and Millard [16]. In 1995, Wong and Zhu reworked the coefficients in this particular algorithm by considering the International Temperature Scale of 1990, and their version of the UNESCO equation is presented below [18]: 
The speed of sound in seawater is already presented in Equation (9) above. In that particular notation, $C_{w}$ is the speed of sound in pure water, whereas $\mathrm{A}, \mathrm{B}$, and D are terms related to salinity.

$$
\begin{gathered}
C(T, P)=\left(C_{00}+C_{01} T+C_{02} T^{2}+C_{03} T^{3}+C_{04} T^{4}+C_{05} T^{5}\right)+ \\
\left(C_{10}+C_{11} T+C_{12} T^{2}+C_{13} T^{3}+C_{14} T^{4}\right) P+ \\
\left(C_{20}+C_{21} T+C_{22} T^{2}+C_{23} T^{3}+C_{24} T^{4}\right) P^{2}+ \\
\left(C_{30}+C_{31} T+C_{32} T^{2}\right) P^{3} \\
A(T, P)=\left(A_{00}+A_{01} T+A_{02} T^{2}+A_{03} T^{3}+A_{04} T^{4}\right)+ \\
\left(A_{10}+A_{11} T+A_{12} T^{2}+A_{13} T^{3}+A_{14} T^{4}\right) P+ \\
\left(A_{20}+A_{21} T+A_{22} T^{2}+A_{23} T^{3}\right) P^{2}+ \\
\left(A_{30}+A_{31} T+A_{32} T^{2}\right) P^{3} \\
B(T, P)=B_{00}+B_{01} T+\left(B_{10}+B_{11} T\right) P \\
D(T, P)=D_{00}+D_{10} P
\end{gathered}
$$

$\mathrm{T}$ is the temperature represented in degrees Celsius, $\mathrm{S}$ is the salinity represented in Practical Salinity Unit parts per thousand (ppt), and P represents pressure, computed in bar $\mathrm{kPa}$. The range of validity for temperature varies from 0 to $40{ }^{\circ} \mathrm{C}$, that for salinity varies from 0 to 40 parts per thousand (ppt), and that for pressure is from 0 to 1000 bar.

\subsubsection{SSP Computations Using the Del Grosso Equation (1974)}

There is another equation regarded as a substitute for the UNESCO algorithm, called the Del Grosso Equation (1974). This equation was also reworked by Wong and Zhu (1995) for the new International Temperature Scale of 1990, and it is given as follows $[17,18]$.

$$
\begin{gathered}
c(S, T, P)=C_{000}+\Delta C_{T}+\Delta C_{S}+\Delta C_{P}+\Delta C_{S T P} \\
\Delta C_{T}(T)=C_{T 1} T+C_{T 2} T^{2}+C_{T 3} T^{3} \\
\Delta C_{S}(S)=C_{S 1} S+C_{S 2} S^{2} \\
\Delta C_{P}(P)=C_{P 1} P+C_{P 2} P^{2}+C_{P 3} P^{3} \\
\Delta C_{S T P}(S, T, P)=C_{T P} T P+C_{T 3 P} T^{3} P+C_{T P 2} T P^{2}+C_{T 2 P 2} T^{2} P^{2}+C_{T P 3} T P^{3}+ \\
C_{S T} S T+C_{S T 2} S T^{2}+C_{S T P} S T P+C_{S 2 T P} S^{2} T P+C_{S 2 P 2} S^{2} P^{2}
\end{gathered}
$$

$\mathrm{T}$ represents the temperature in degrees Celsius, $\mathrm{S}$ exhibits the salinity in Practical Salinity Units, and $\mathrm{P}$ illustrates the pressure in $\mathrm{kg} / \mathrm{cm}^{2}$. The range of validity for temperature is 0 to $30^{\circ} \mathrm{C}$, whereas that for salinity is 30 to 40 parts per thousand, and that for pressure is 0 to $1000 \mathrm{~kg} / \mathrm{cm}^{2}$, where $100 \mathrm{kPa}$ $=1.019716 \mathrm{~kg} / \mathrm{cm}^{2}$.

\section{Results}

This section presents outcomes which are categorized initially for a depth of $4000 \mathrm{~m}$, followed by $6000 \mathrm{~m}$, displaying the outcomes of basic first-order extrapolations as well as the improved second-order ones. As a special case scenario, three floats (WMO5905738, WMO5905739, WMO5905740) with profiling depths of up to $\sim 5000 \mathrm{~m}$ were selected in the Pacific Ocean for two particular activities. The first activity was to illustrate the wider spatiotemporal coverage by employing extrapolation for one of these three floats i.e., WMO5905738 (considering 10, 11, and 18 cycles). Furthermore, these three floats were employed for asymmetric extrapolations, and the outcomes proved to be almost identical to the in situ values of floats. 


\subsection{Extrapolations and Their Subsequent Rectifications for $4000 \mathrm{~m}$ Floats}

The details of the Argo floats employed for computations in the category of $4000 \mathrm{~m}$ are detailed in Table 1, which lists the relative float identities, cycle numbers, date, and latitude and longitude, along with the locations of these floats. Initially, the salinities for these floats are illustrated as in situ measured and first-order extrapolations by computing values for $m=1$, along with comparative analysis of improved second-order extrapolations produced using $m=2$ in $(\mathrm{a}, \mathrm{b})$, respectively, of Figures 1-3. The temperatures for floats exhibited in Table 1 are illustrated in a similar manner in (c,d) of Figures 1-3. Likewise, the sound speed profiles for such floats were computed and extrapolated in the aforementioned ways and illustrated as their first-order extrapolations using Chen and Miller (1977) [14] and the UNESCO algorithm [15,16] in (a,b), respectively, of Figures 4-6. However, Del Gross (1974) is exhibited for both in situ measured and first-order extrapolations, as well as with improved second-order extrapolations, in (c,d), respectively, in Figures 4-6. It is pertinent to mention here that the Del Grosso equation $[15,16]$ was considered since it offers a relatively better SSP estimation for acoustically returning patterns in comparison to Chen and Millero (1977) [21]. The values of $m$ are discussed above, whereas the values of $n$ for WMO2902510, WMO2902971, and WMO19274 were 32, 78 , and 14 , respectively.

Table 1. This table presents details of the floats diving to depths of $4000 \mathrm{~m}$.

\begin{tabular}{lcccc}
\hline Float Identity & Cycle Number & Date & Lat, Long. & Location \\
\hline WMO2902510 & 24 & 2 March 2014 & 30.447 N, 146.004 E & Pacific Ocean \\
WMO2902971 & 08 & 12 May 2016 & 29.566 N, 146.364 E & Pacific Ocean \\
WMO1902074 & 08 & 11 April 2016 & 28.998 S, 52.16 E & Indian Ocean \\
\hline
\end{tabular}

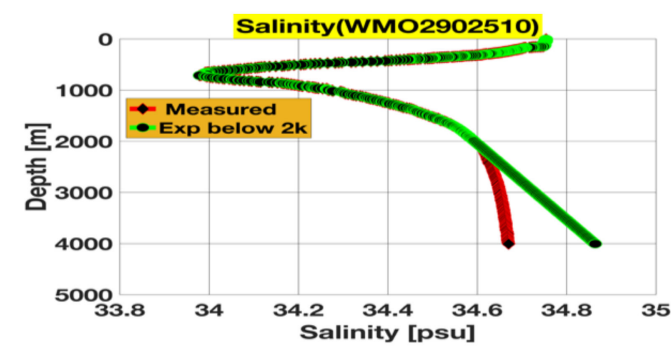

(a)

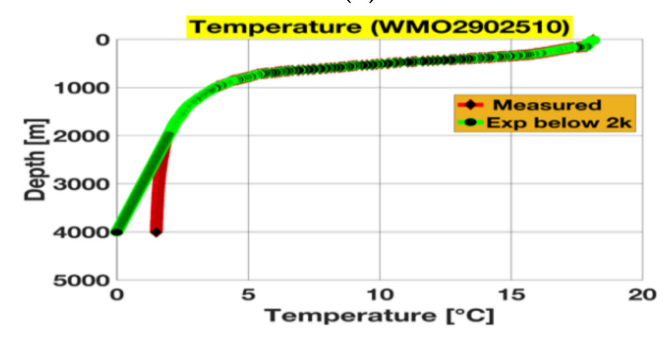

(c)

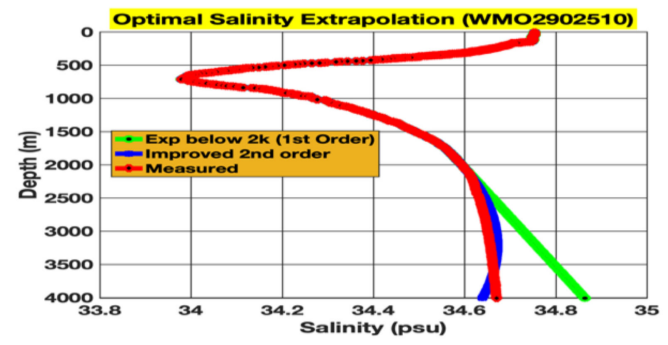

(b)

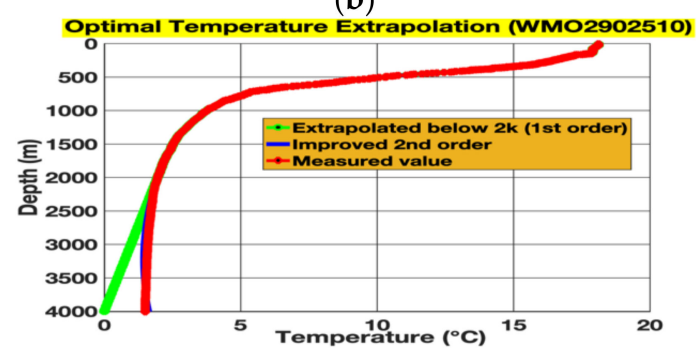

(d)

Figure 1. The in situ measured and extrapolated salinities and temperature both by first-order and by improved second-order extrapolation $(\mathbf{a}, \mathbf{b})$ for the salinities where a difference of $\sim 0.2$ psu was reduced to a negligible level after improved second-order rectification and, similarly, (c,d) for temperatures where a difference of $\sim 1.5^{\circ} \mathrm{C}$ due to basic first-order extrapolation was reduced to an infinitesimal amount by second-order extrapolation. 


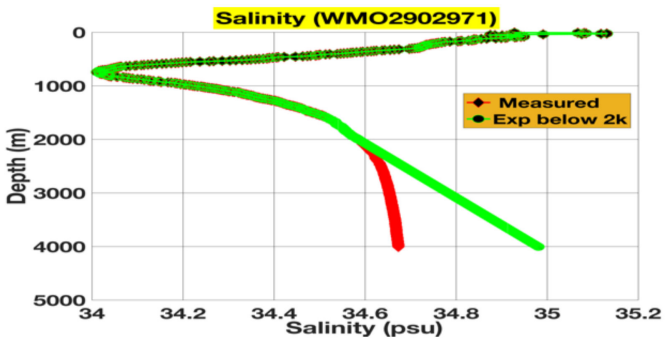

(a)

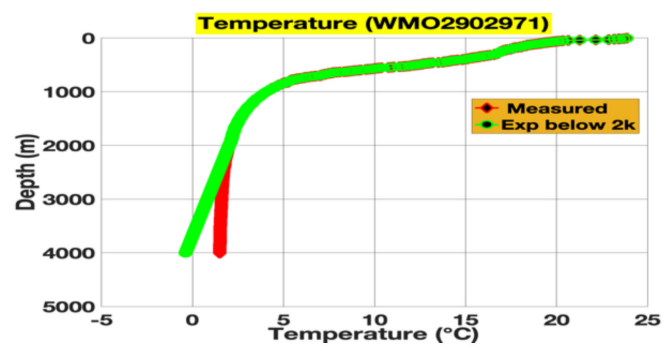

(c)

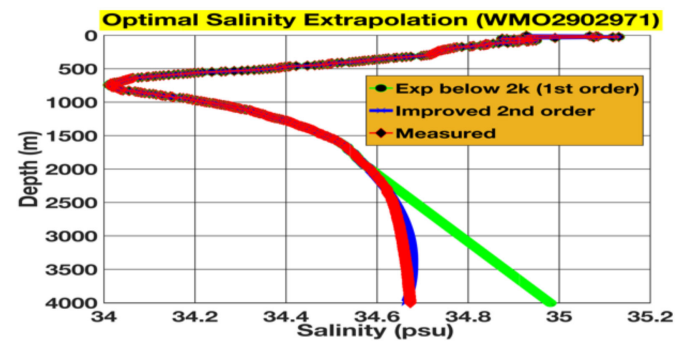

(b)

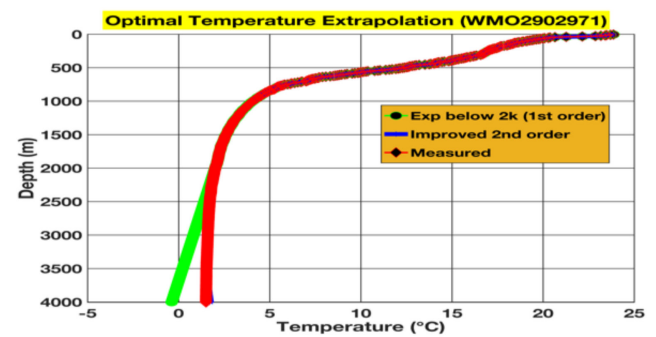

(d)

Figure 2. The in situ measured and extrapolated salinities and temperature both by first-order and by improved second-order extrapolation $(\mathbf{a}, \mathbf{b})$ for the salinities, where a difference of $\sim 0.3$ psu due to basic first order was reduced to a negligible amount after improved second-order rectification and, similarly, (c,d) for temperatures, where a difference of $\sim 1.3^{\circ} \mathrm{C}$ due to basic first-order extrapolation was reduced to an infinitesimal amount by second-order extrapolation.

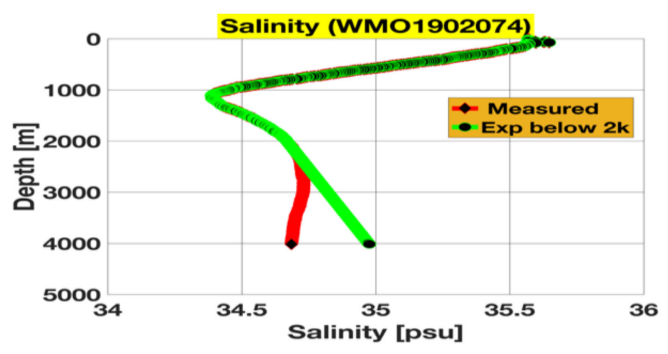

(a)

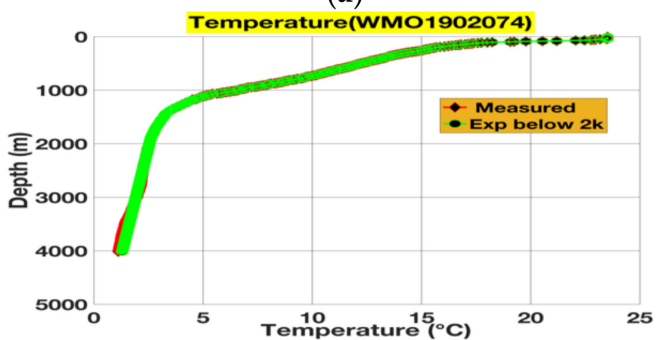

(c)

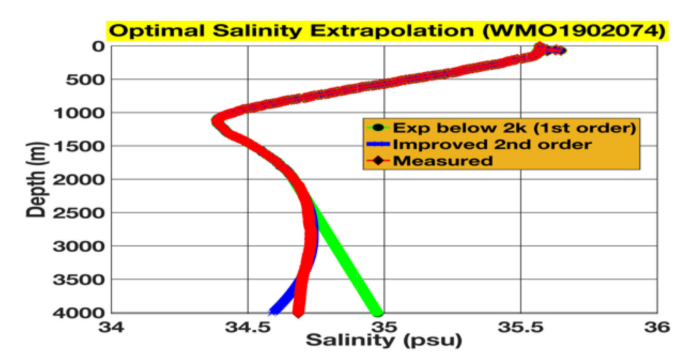

(b)

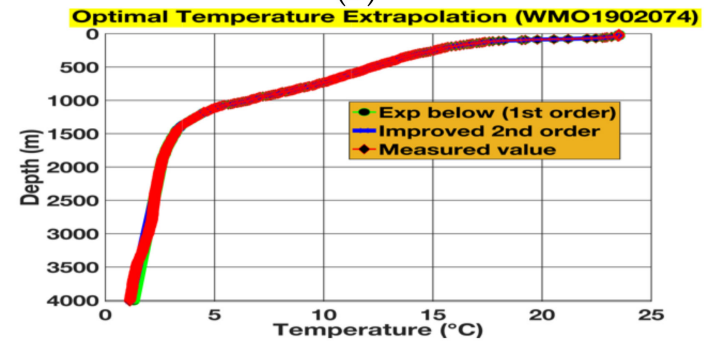

(d)

Figure 3. The in situ measured and extrapolated salinities and temperature both by first-order and by improved second-order extrapolation $(\mathbf{a}, \mathbf{b})$ for the salinities, where a difference of $\sim 0.3$ psu due to basic first order was reduced to a negligible amount by improved second-order rectification and, similarly, (c,d) for temperatures, where a difference of $\sim 1.3{ }^{\circ} \mathrm{C}$ due to basic first-order extrapolation was reduced to an infinitesimal amount by second-order extrapolation. 


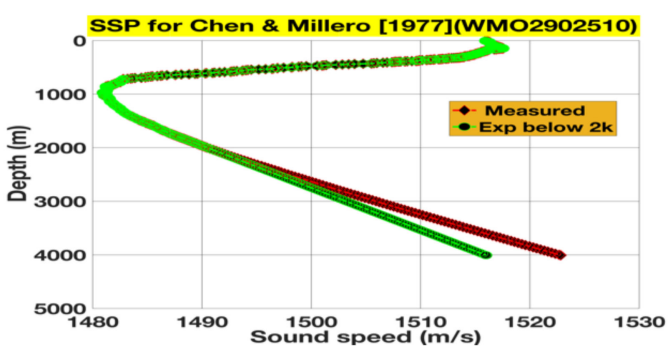

(a)

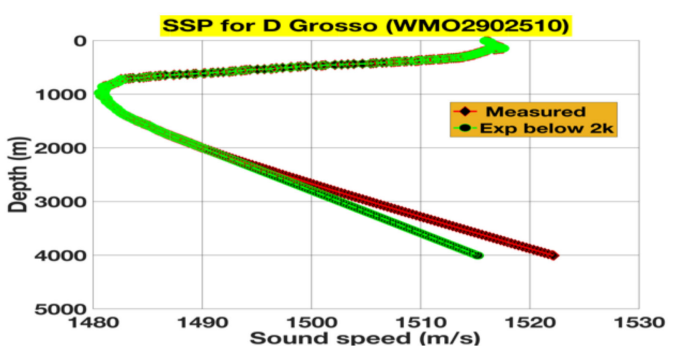

(c)

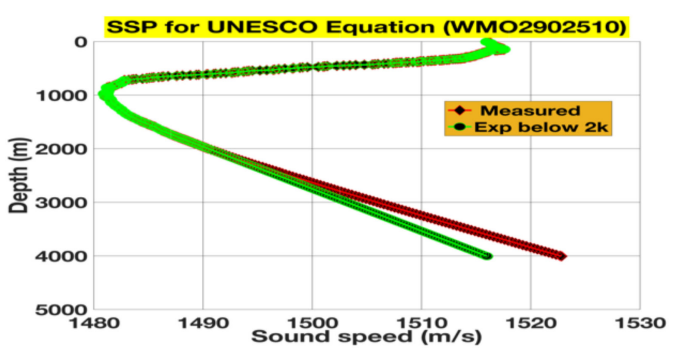

(b)

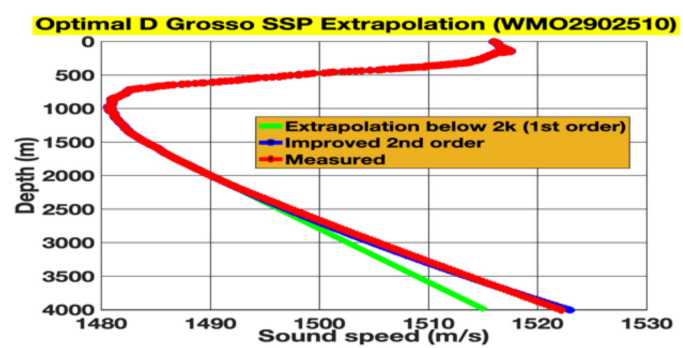

(d)

Figure 4. The sound speed profiles (SSPs) from the various equations computed via first-order extrapolation are illustrated $(\mathbf{a}-\mathbf{c})$. Similarly, the improved second-order extrapolation using the Del Grosso equation is exhibited (d), where the difference was reduced from $\sim 7.5 \mathrm{~m} / \mathrm{s}$ to almost negligible.

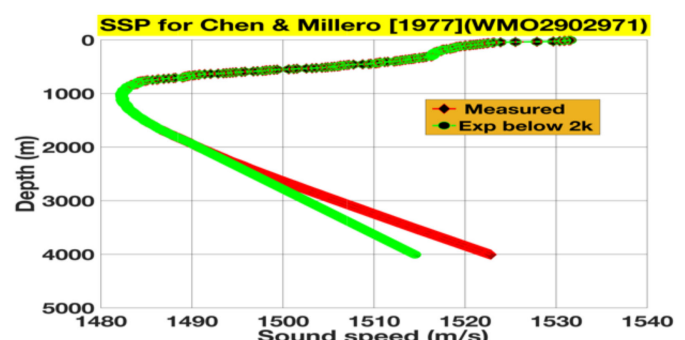

(a)

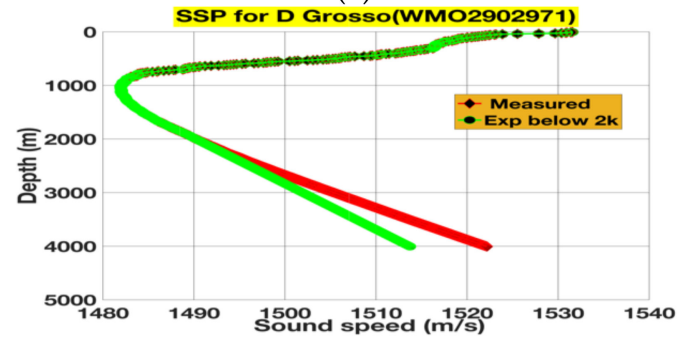

(c)

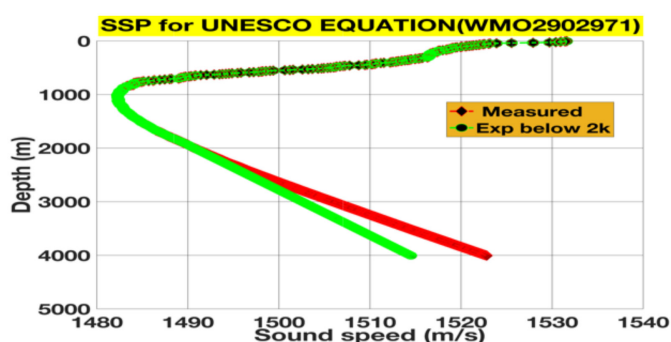

(b)

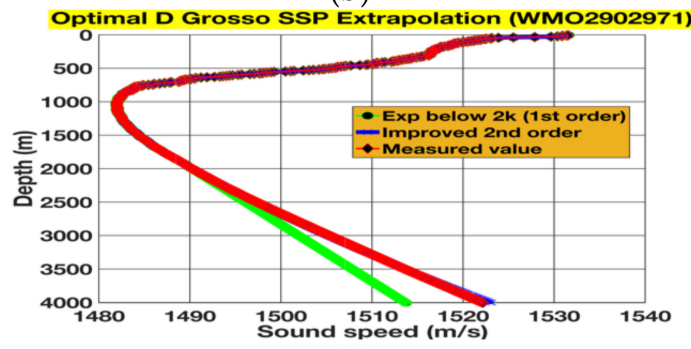

(d)

Figure 5. The SSPs from the various equations computed via first-order extrapolation are illustrated $(\mathbf{a}-\mathbf{c})$. Similarly, the improved second order-extrapolation using the Del Grosso equation is exhibited (d), where a difference of $\sim 8.5 \mathrm{~m} / \mathrm{s}$ was reduced to be almost negligible. 


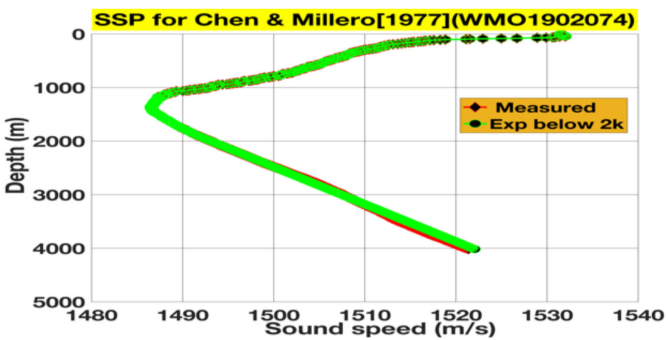

(a)

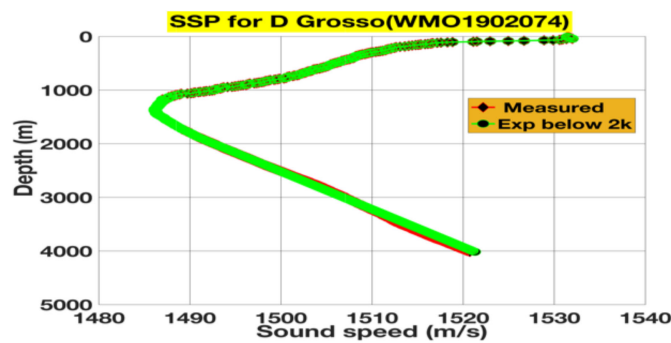

(c)

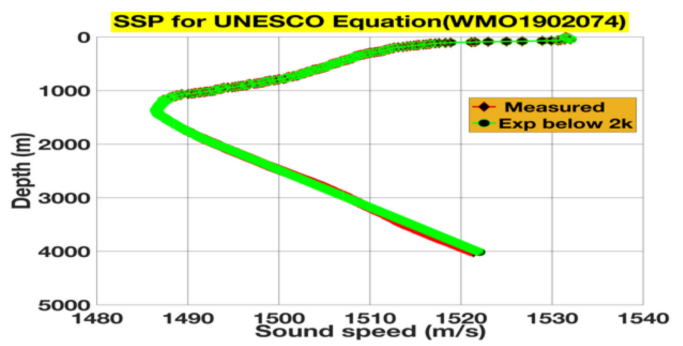

(b)

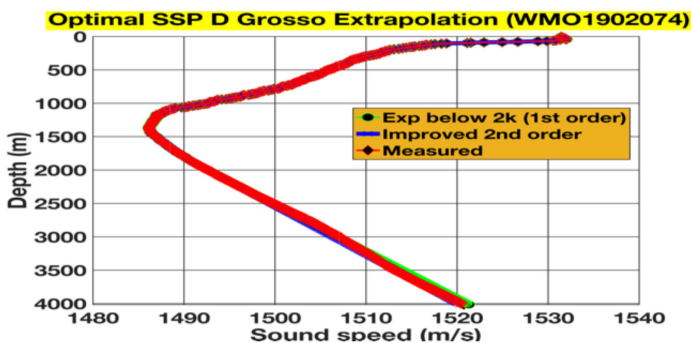

(d)

Figure 6. The SSPs from the various equations computed via first-order extrapolation are illustrated $(\mathbf{a}-\mathbf{c})$. Similarly, the improved second-order extrapolation using the Del Grosso equation is exhibited (d), where the improved extrapolation is almost identical to the real in situ measured value, unlike the basic first-order extrapolation.

\subsection{Extrapolations and Their Subsequent Rectifications for $6000 \mathrm{~m}$ Floats}

The data from two Argo floats presented in Table 2 were utilized for computations in this particular section to offer profiling floats of CTD for abyssal depths of $6000 \mathrm{~m}$. The scheme of the illustrations follows that of the aforementioned, i.e., $4000 \mathrm{~m}$ floats in Section 3.1. The salinities and temperatures for the aforementioned Argo floats were compared for their measured in situ values using basic first-order extrapolations with $m$ equal to 1 , as well as their rectifications with second-order extrapolations by computing with $m=2$, with $(\mathrm{a}, \mathrm{b})$ presenting salinities and $(\mathrm{c}, \mathrm{d})$ presenting temperatures in Figures 7 and 8. The SSPs for the aforementioned Argo floats are also depicted, just like in the $4000 \mathrm{~m}$ case detailed in Section 3.1. The basic extrapolations were compared by employing the Chen and Millero equation [16] as well as the UNESCO algorithm [17,18], presented in $(a, b)$ of Figures 9 and 10. Similarly, the SSP given by Del Grosso equation $[17,18]$ extrapolation is compared initially with in situ measured data and the first-order basic equation in (c) and with improved second-order extrapolation in (d) of Figures 9 and 10. Similarly, $n$ for the extrapolations of WMO4902322 and WMO5902521 was chosen to be 49 and 35, respectively.

Table 2. This table presents details of the floats diving to the depths of $6000 \mathrm{~m}$.

\begin{tabular}{lcccc}
\hline Float Identity & Cycle Number & Date & Lat, Long. & Location \\
\hline WMO4902322 & 15 & 17 June 2017 & $24.8972 \mathrm{~N}, 58.4255 \mathrm{E}$ & Atlantic Ocean \\
WMO5902521 & 71 & 5 Jane 2019 & 38.7563 S, 128.6227 E & Indian Ocean \\
\hline
\end{tabular}




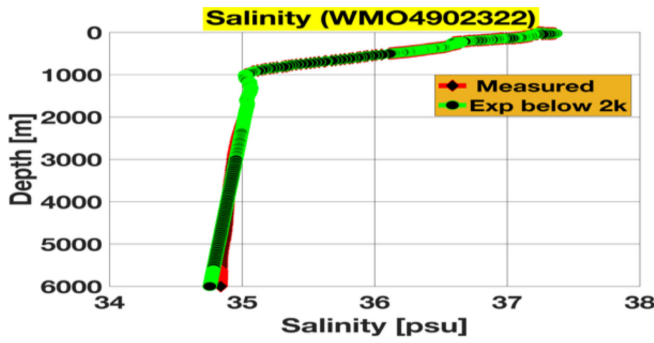

(a)

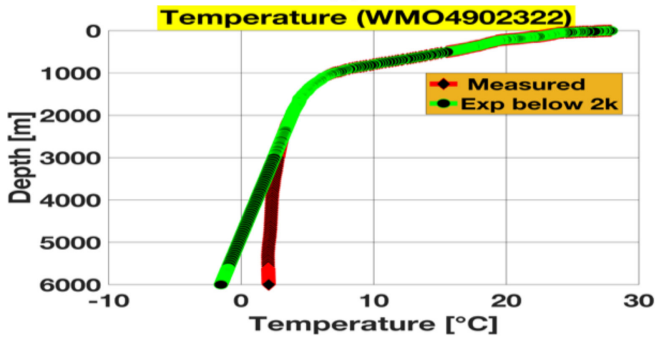

(c)

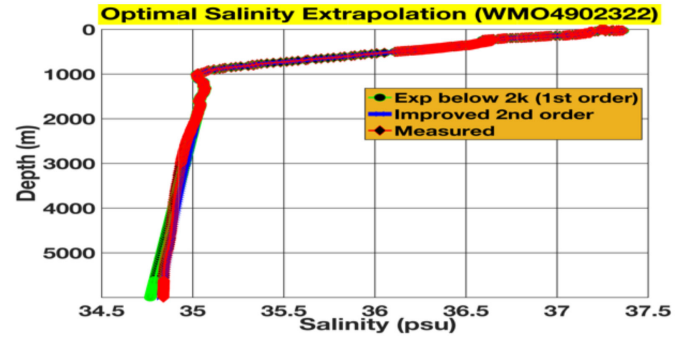

(b)

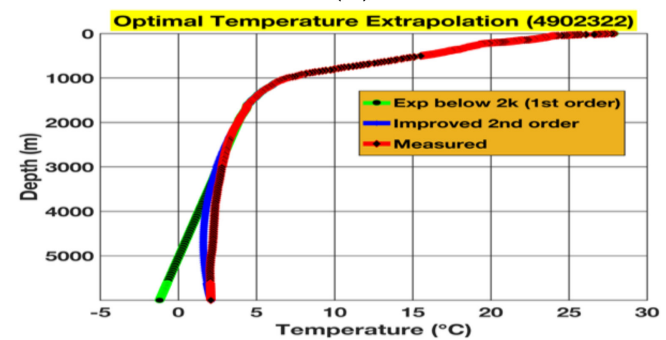

(d)

Figure 7. The in situ measured and extrapolated salinities and temperature both by first-order and by improved second-order extrapolation $(\mathbf{a}, \mathbf{b})$ for the salinities, where a difference of $\sim 0.1$ psu due to basic first-order extrapolation was reduced to a negligible amount after improved second-order rectification and, similarly, (c,d) for temperatures, where a difference of $\sim 4^{\circ} \mathrm{C}$ due to basic first-order extrapolation was reduced to an infinitesimal amount by second-order extrapolation at $6000 \mathrm{~m}$ depth. However, a deviation was observed at 3000-5000 $\mathrm{m}$ depth with a maximum of $\sim 2{ }^{\circ} \mathrm{C}$.

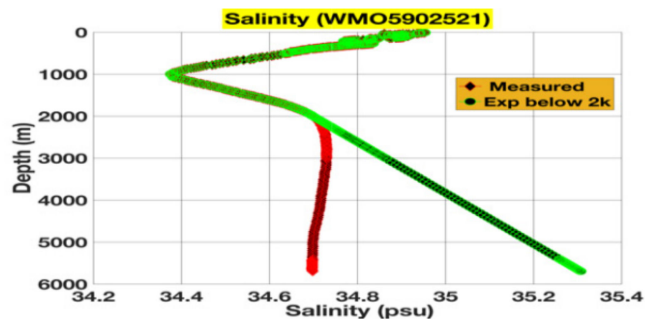

(a)

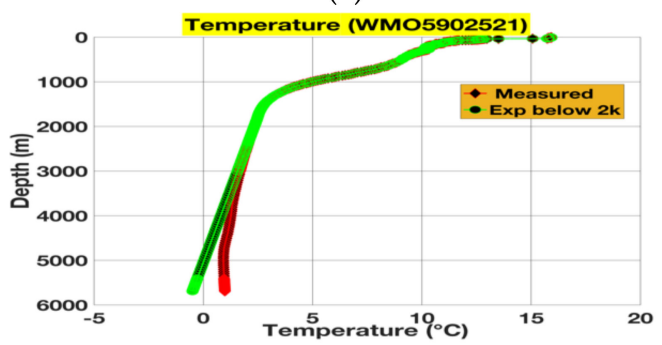

(c)

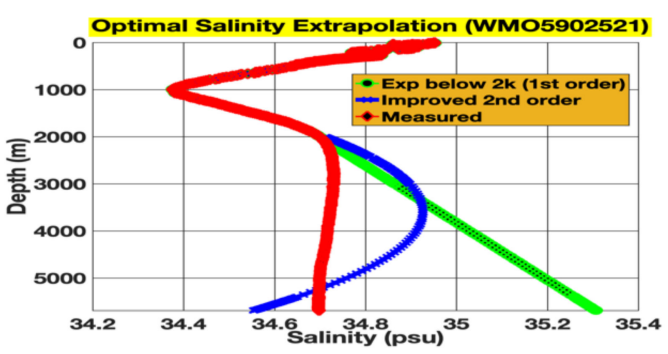

(b)

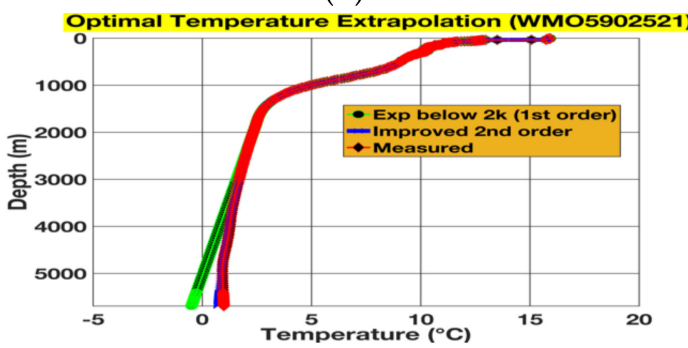

(d)

Figure 8. The in situ measured and extrapolated salinities and temperature both by first-order and by improved second-order extrapolation $(\mathbf{a}, \mathbf{b})$ for the salinities, where a difference of $\sim 0.6$ psu due to basic first-order extrapolation was comparatively improved to $\sim 0.15 \mathrm{psu}$ at $6000 \mathrm{~m}$ depth, though apparent deviations persist for 2000-5200 m with a max deviation of $\sim 0.22 \mathrm{psu}$. Similarly, (c,d) for temperatures, a difference of $\sim 1^{\circ} \mathrm{C}$ due to basic first-order extrapolation was reduced to be negligible all along the depth just below $2000 \mathrm{~m}$ from where the extrapolation initiated. 


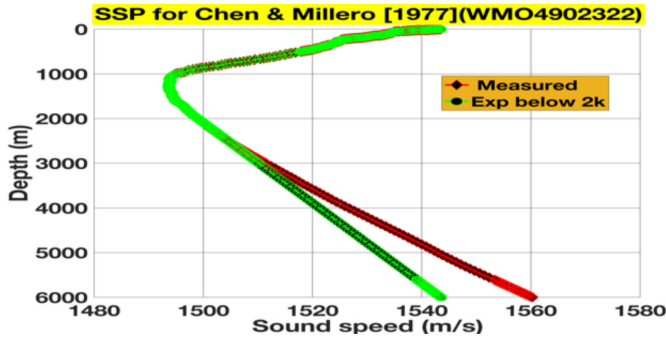

(a)

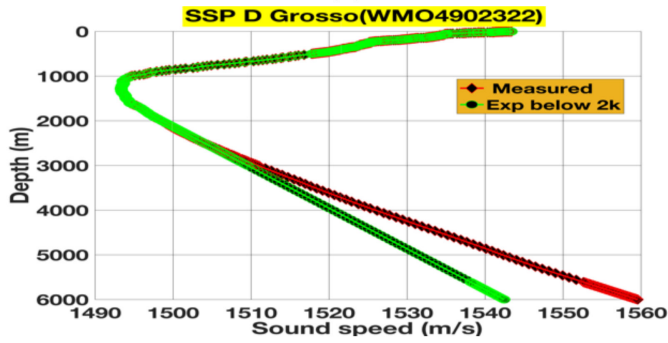

(c)

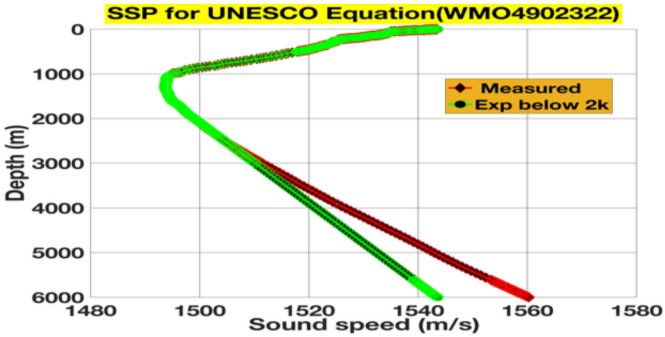

(b)

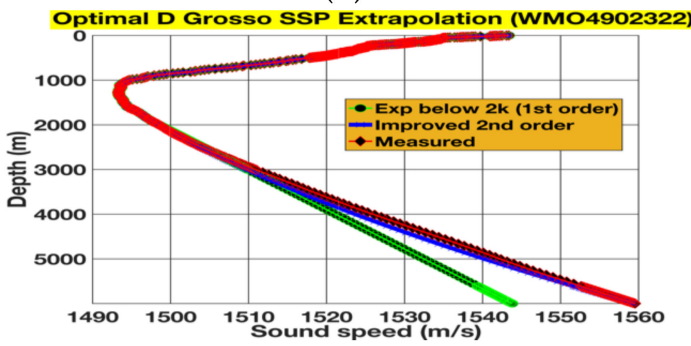

(d)

Figure 9. The SSPs from the various equations computed via first-order extrapolation are illustrated $(\mathbf{a}-\mathbf{c})$. Similarly, the improved second-order extrapolation using the Del Grosso equation is exhibited (d), where a difference of $\sim 16 \mathrm{~m} / \mathrm{s}$ was reduced to be almost negligible at $6000 \mathrm{~m}$ depth while exhibiting fewer deviations at depths of 3300-5500 $\mathrm{m}$.

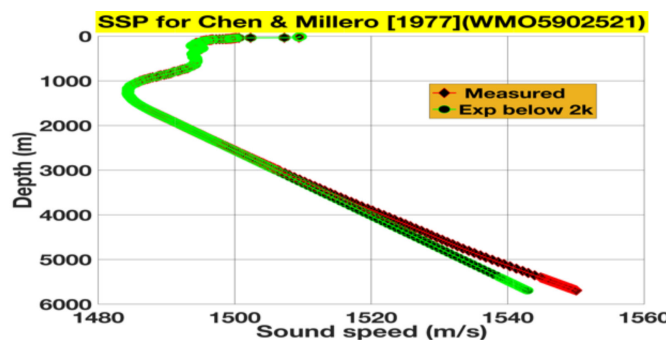

(a)

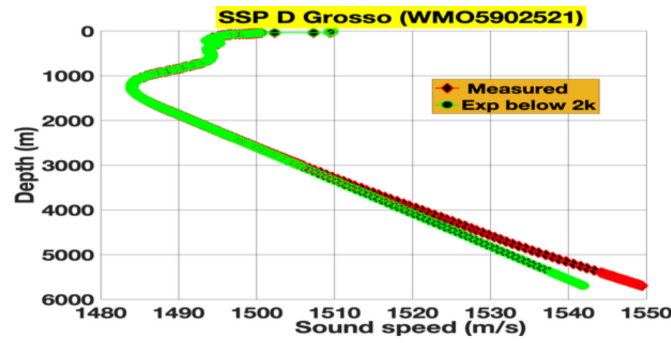

(c)

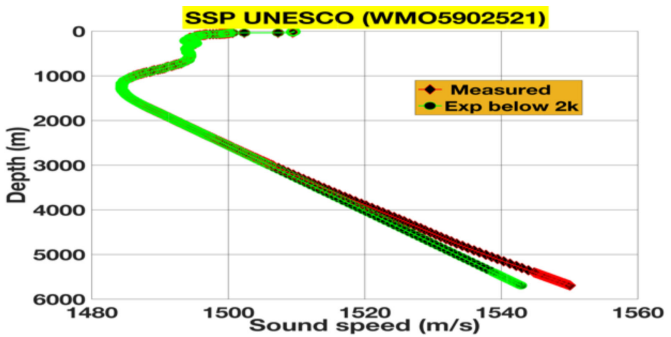

(b)

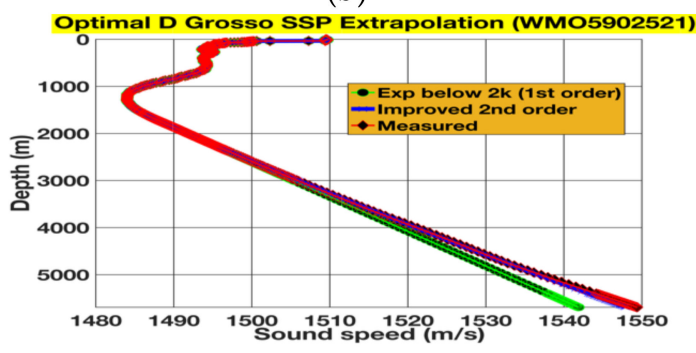

(d)

Figure 10. The SSPs from the various equations computed via first-order extrapolation are illustrated $(\mathbf{a}-\mathbf{c})$. Similarly, the improved second-order extrapolation using the Del Grosso equation is exhibited (d), where a difference of $\sim 6 \mathrm{~m} / \mathrm{s}$ was reduced to an almost negligible amount.

\subsection{Experimentation in the Pacific Ocean for Spatiotemporal Coverage and Asymmetric Rectification}

This section focuses on three floats, i.e., WMO5905738, WMO5905739, and WMO5905740, located in the midst of the Pacific Ocean and with profiling depths of up to $\sim 5000 \mathrm{~m}$. One of these floats, WMO5905738, was employed to extrapolate its varying cycles with the aim to demonstrate wider spatiotemporal coverage in terms of salinities and SSPs. Similarly, the aforementioned three floats were employed to exhibit rectifications of discrepancies by asymmetric extrapolations as compared to symmetric ones. 


\subsubsection{Spatiotemporal Coverage through Extrapolations}

As discussed above, varying cycles of an Argo float (WMO5905738) were extrapolated in order to illustrate wider spatiotemporal coverage by employing the proposed method. The details of the cycles, their latitude and longitude, and the date and time are presented in Table 3. The $m$ and $n$ values varied for varying cycles of this particular float, i.e., cycle $10(m=3$ and $n=112)$, with temperature and SSP shown in Figure 11a,b, cycle $11(m=3$ and $n=52)$, with temperature and SSP illustrated in Figure 11c,d, and cycle 18 ( $m=2$ and $n=38)$, with temperature and SSP depicted in Figure 11e,f. It is worth mentioning that the extrapolations produced in this particular activity showed remarkable outcomes, especially to the abyssal depth of $4000 \mathrm{~m}$. This particular activity illustrates the application of extrapolations on varying cycles of the floats to acquire broader spatiotemporal coverage of the abyssal depths of the ocean in certain regions. A deep in situ reference in the vicinity is required, as well as Core Argo buoys with depth $2000 \mathrm{~m}$. The analysis in this particular section is focused on temperature and the subsequently computed SSPs since the role of salinity is minimal in deducing SSPs, as observed from the aforementioned computations and the literature [22,23].

Table 3. This table presents details of the floats in the Pacific Ocean.

\begin{tabular}{ccccc}
\hline Float Identity & Cycle & Lat, Long. & Date & Time \\
\hline WMO5905738 & 10 & $22.9324 \mathrm{~N}, 158.5839 \mathrm{~W}$ & 31 May 2018 & $05: 43: 00$ \\
WMO5905738 & 11 & $22.9638 \mathrm{~N}, 158.705 \mathrm{~W}$ & 5 June 2018 & $02: 14: 00$ \\
WMO5905738 & 18 & $22.9121 \mathrm{~N}, 158.715 \mathrm{~W}$ & 9 July 2018 & $14: 39: 00$ \\
\hline
\end{tabular}

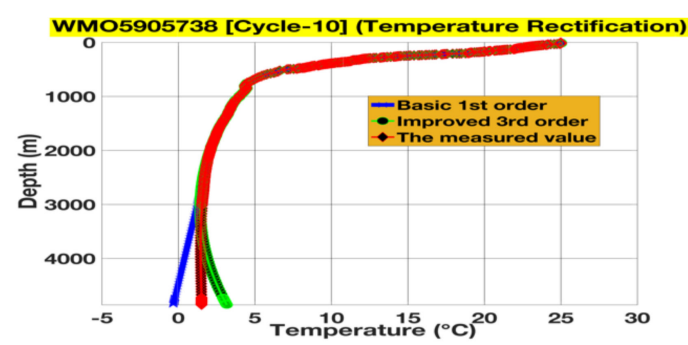

(a)

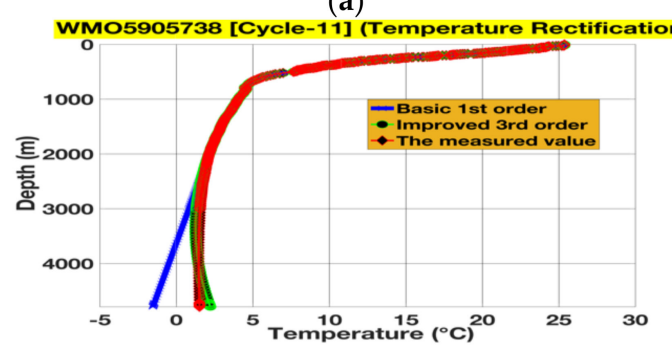

(c)

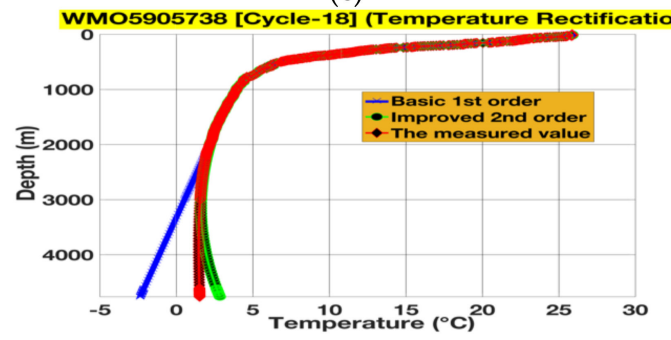

(e)

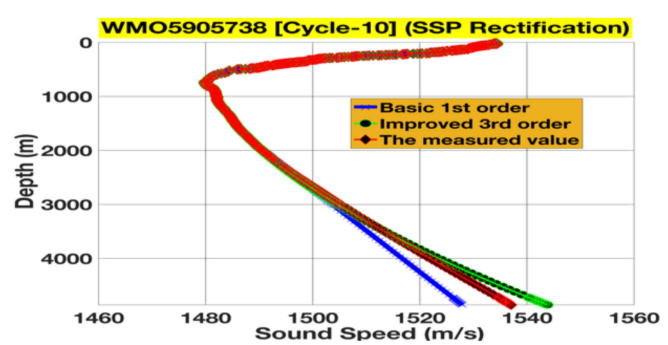

(b)

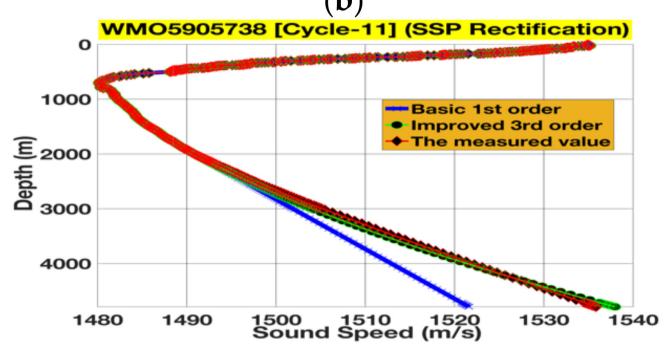

(d)

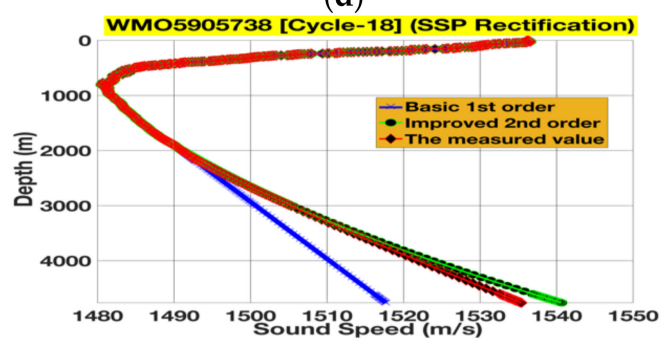

(f)

Figure 11. The temperatures and SSPs for varying cycles of WMO5905738 are illustrated (a,c), along with (e) in situ, basic first-order extrapolated, and improved second-order extrapolated temperatures, with discrepancies of $\sim 6^{\circ} \mathrm{C}$ rectified to $\sim 2{ }^{\circ} \mathrm{C}$ values. Similarly, the SSPs improved from $\sim 9 \mathrm{~m} / \mathrm{s}$ max to $\sim 3 \mathrm{~m} / \mathrm{s}$, as illustrated in (b,d, and $\mathbf{f})$. 


\subsubsection{Symmetric and Asymmetric SSP Rectifications}

This particular section compares the extrapolation rectifications of SSPs, both symmetrically and asymmetrically. The floats for this typical activity, along with their cycles, latitude and longitude, and time are illustrated in Table 4 . In this activity, the same floats were initially rectified using fixed values of both $m$ and $n$, which were 2 and 40, respectively; this is illustrated in Figure 12a,c,e. However, both $m$ and $n$ were varied for the various floats, i.e., for WMO5905738 ( $m=2$ and $n=46)$, for WMO5905739 ( $m=3$ and $n=68$ ), and for WMO5905740 ( $m=2$ and $n=37$ ); this is depicted in Figure $12 \mathrm{~b}$,d,f. It is pertinent to mention that by varying the values of both $m$ and $n$, i.e., by rectifying asymmetrically, the achieved rectified values were almost analogous to the in situ measured values of the floats.

Table 4. This table presents details of the floats in the Pacific Ocean.

\begin{tabular}{ccccc}
\hline Float Identity & Cycle & Lat, Long. & Date & Time \\
\hline WMO5905738 & 20 & $22.6443 \mathrm{~N}$, 158.6656 W & 19 July 2018 & 11:52:11 \\
WMO5905739 & 20 & $22.8836 \mathrm{~N}, 158.7888 \mathrm{~W}$ & 3 July 2018 & 04:03:52 \\
WMO5902521 & 20 & 12.0588 N, 154.0620 W & 19 September 2018 & 07:54:23 \\
\hline
\end{tabular}

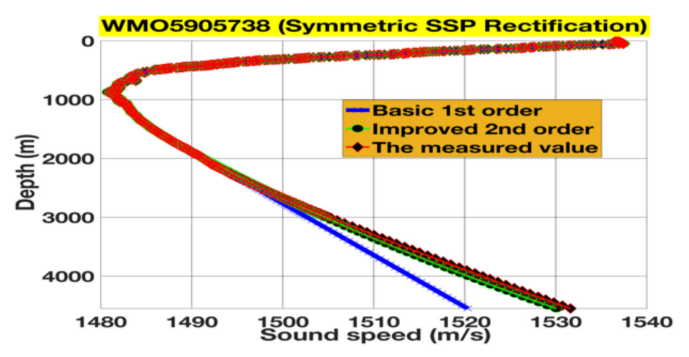

(a)

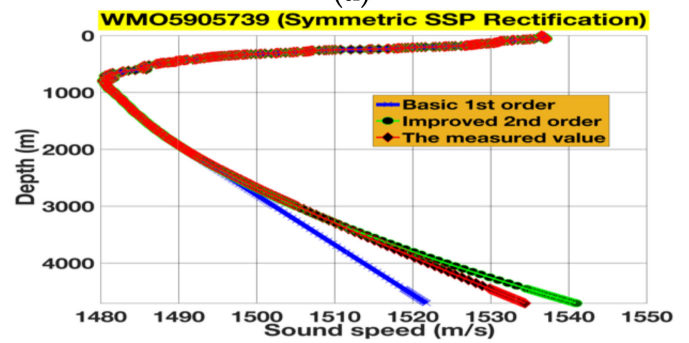

(c)

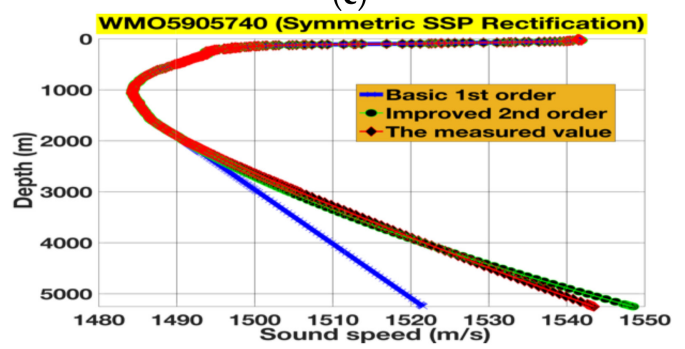

(e)

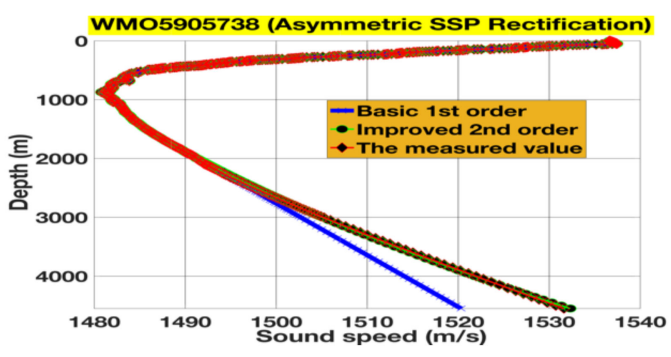

(b)

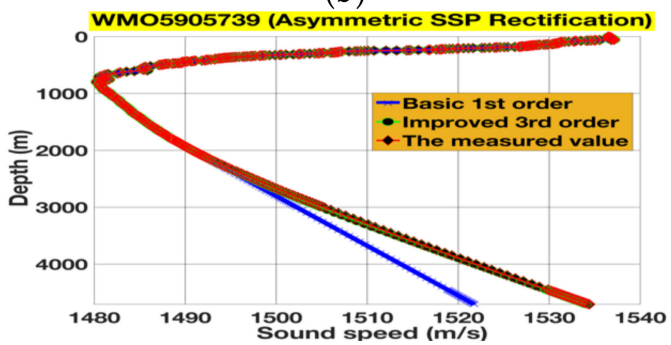

(d)

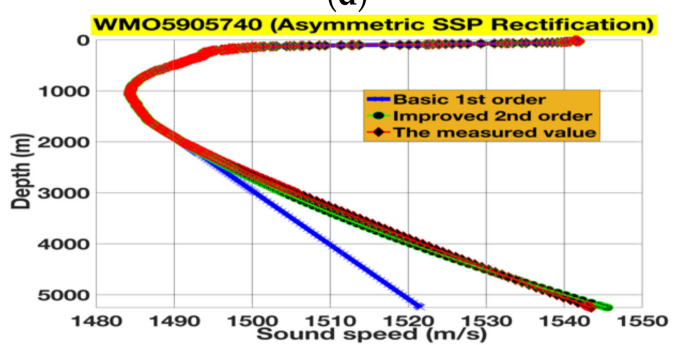

(f)

Figure 12. The SSPs from symmetric extrapolations were rectified by asymmetric extrapolation, resulting in an improvement of $\sim 2 \mathrm{~m} / \mathrm{s}$ to become almost identical $(\mathbf{a}, \mathbf{b})$. Similarly, an improvement was observed from $\sim 7 \mathrm{~m} / \mathrm{s}$ to negligible difference $(\mathbf{c}, \mathbf{d})$. Finally, a difference of $\sim 5 \mathrm{~m} / \mathrm{s}$ was improved to $\sim 1 \mathrm{~m} / \mathrm{s}$, as illustrated in $(\mathbf{e}, \mathbf{f})$, respectively.

\section{Discussion}

The study illustrates promising outcomes, and the presented method can be employed for optimum extrapolations in global abyssal oceans to offer better approximation of the vertical profiles 
of salinity, temperature, and SSPs. The limitations of this particular method are the availability of abyssal reference inputs at the desired depths to ascertain the extrapolations and the reliance on varying Core Argo floats at $2000 \mathrm{~m}$ depth for further computations. The Deep Argo array is in the process of deployment and even after its deployment will remain sparsely populated $\left(5^{\circ}\right.$ latitude $\times$ $5^{\circ}$ longitude $\times 15$-day cycles) compared to the Core Argo array ( $3^{\circ}$ latitude $\times 3^{\circ}$ longitude $\times 10$-day cycles) $[13,15]$. This method, in turn, is capable of filling the gaps in both the temporal and spatial scales by extrapolating to optimum levels, as illustrated in the outcomes detailed herein for varying Argo floats.

Transmission loss rectifications are displayed for a source depth of $300 \mathrm{~m}$ and frequency of $50 \mathrm{~Hz}$ in Figure 13 by employing a float (WMO2902510 with cycle 24), illustrated in (a), with measured in situ values of transmission loss exhibited in (b); computations employing $m=1$ and $n=32$ are shown in (c), and improved extrapolations and transmission loss computations with $m=2$ and $n=32$ are depicted in (d). This activity may be conducted for various locations and for wider regions based on extrapolations as a future course of action.

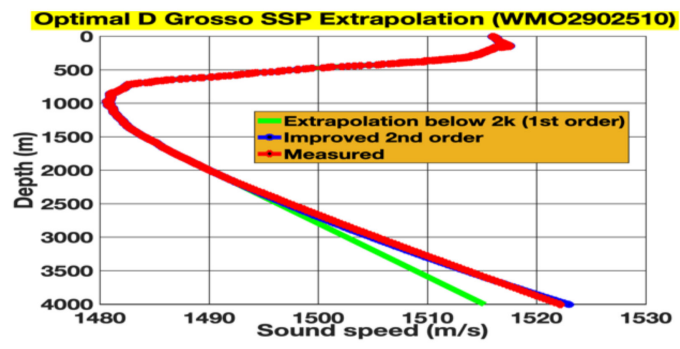

(a)

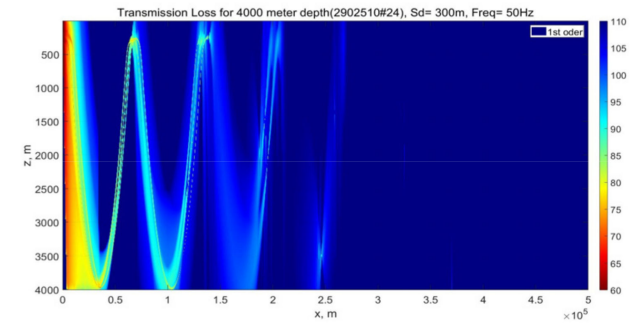

(c)

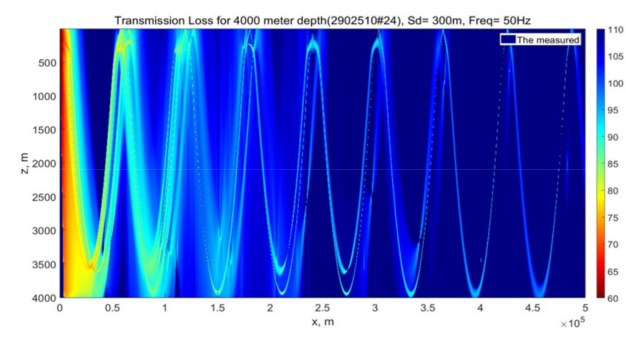

(b)

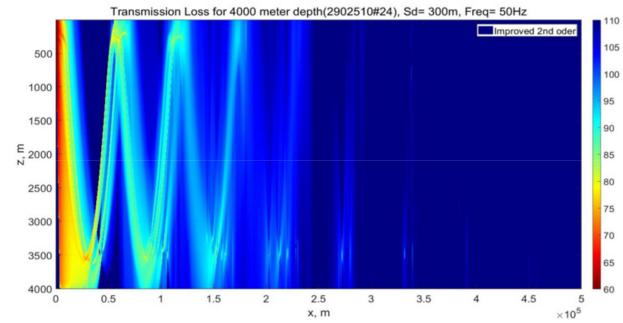

(d)

Figure 13. For the transmission loss computation, accordingly, (a) illustrates the measured, basic first-order extrapolated, and improved second-order extrapolated SSPs. Similarly, the transmission loss based on in situ measured values is exhibited in (b). The transmission loss after employing the first-order extrapolation is presented in (c). Finally, the transmission loss with improved second-order extrapolation is illustrated in (d).

\section{Conclusions}

Deep ocean observations are of utmost importance for both scientific and seasonal requirements. In this context, in this study, we took advantage of both the Deep Argo and Core Argo programs to cover vertical CTD profiles and SSPs of the abyssal oceans using as accurate extrapolations as possible. The study was initiated with a novel approach of extrapolating the aforementioned parameters by employing the least squares method in deeper oceans and then rectifying the remaining discrepancies via symmetric and asymmetric extrapolations. We rectified discrepancies of salinity on the order of $\sim 0.3 \mathrm{psu}$ to negligible values for depths of $4000 \mathrm{~m}$ and from $\sim 0.6 \mathrm{psu}$ to minute values for $6000 \mathrm{~m}$. Likewise, the temperatures were rectified on the order of $\sim 1.5^{\circ} \mathrm{C}$ at maximum to negligible for $4000 \mathrm{~m}$ and from $\sim 4{ }^{\circ} \mathrm{C}$ at maximum to almost perfect accuracy for $6000 \mathrm{~m}$ depths. It is pertinent to mention that the discrepancies in the SSPs rectified for the $4000 \mathrm{~m}$ Argo floats were $\sim 8.5 \mathrm{~m} / \mathrm{s}$ and $\sim 16 \mathrm{~m} / \mathrm{s}$ for the $6000 \mathrm{~m}$ floats. The asymmetric extrapolations for the SSP were improved from $\sim 7 \mathrm{~m} / \mathrm{s}$ to negligible 
values as compared to the symmetric extrapolations. Similarly, we conducted experiments on varying cycles of a float to prove the wider spatiotemporal extrapolation capability of this particular method in certain regions based on the availability of abyssal ocean in situ data and the Core Argo profiles in that particular vicinity. Finally, we concluded with an example of transmission loss rectification capability, which can be addressed as a future course of action based on this particular research. The evolutionary process of extrapolations conducted in this specific study ingeniously conjoins the Core Argo $\left(3^{\circ}\right.$ latitude $\times 3^{\circ}$ longitude $\times 10$-day cycles) and Deep Argo programs ( $5^{\circ}$ latitude $\times 5^{\circ}$ longitude $\times 15$-day cycles) to offer broader coverage on both the spatial and temporal scales in global abyssal oceans. Similarly, transmission loss computations based on these extrapolations are presented as a future course of action.

Author Contributions: Contributions from all the authors were of equal importance with utmost sincerity and dedication. Conceptualization, S.P. and K.I.; Methodology, M.Z. K.I.; Software, M.Z.; Validation, S.P. and K.I.; Formal Analysis, M.Z.; Investigation, M.Z. and K.I.; Resources, S.P. and M.Z.; Data Curation, K.I. and M.Z.; Writing-Original Draft Preparation, K.I.; Writing-Review and Editing, K.I. and M.Z.; Visualization, M.Z.; Supervision, S.P.; Project Administration, S.P.; Funding Acquisition, S.P. In addition, all authors have gone through this particular manuscript and approved it accordingly. All authors have read and agreed to the published version of the manuscript.

Funding: This research was funded by the National Key Research Program, grant number 2016YFC1400100, the Youth Program of the National Nature Science Foundation of China, grant number 11904065, and the National Defense Key Laboratory of Science and Technology Foundation of Electronic Test Technology, grant number 6142001180411.

Conflicts of Interest: The authors declare no conflict of interest.

\section{References}

1. Iqbal, K.; Zhang, M.; Piao, S.; He, G. Gradual but Persistent Quest for the Ocean Observation by Employing Multifarious Sensing Gadgets: A Preview. In Proceedings of the OCEANS 2019-Marseille, Marseille, France, 17-20 June 2019. [CrossRef]

2. Iqbal, K.; Zhang, M.; Piao, S.; He, G. Advent of Deep Argo Data \& an Attempt at Analyzing the Deeper Sound Speed Profiles for Extrapolation Corrections. Underwater Acoustics Conference \& Exhibition, UACE2019, Conference Proceedings. ISSN: 2408-0195, HERSONISSOS, CRETE—GREECE|30.06—05.07.2019. Available online: http://www.uaconferences.org/docs/2019_papers/UACE2019_1007_Iqbal.pdf (accessed on 1 September 2020).

3. Roemmich, D.; Johnson, G.; Riser, S.; Davis, R.E.; Gilson, J.; Owens, W.B.; Garzoli, S.L.; Schmid, C.; Ignaszewski, M. The Argo Program: Observing the Global Oceans with Profiling Floats. Oceanography 2009, 22, 34-43. [CrossRef]

4. Gasparin, F.; Hamon, M.; Rémy, E.; Le Traon, P.-Y. How Deep Argo Will Improve the Deep Ocean in an Ocean Reanalysis. J. Clim. 2019, 33, 77-94. [CrossRef]

5. Katsaros, K. BOOK REVIEW|Atmosphere-Ocean Interactions (Volume 1). Oceanography 2003, 16, $106-108$. [CrossRef]

6. Bigg, G.R.; Jickells, T.D.; Liss, P.S.; Osborn, T.J. The role of the oceans in climate. Int. J. Clim. 2003, 23, 1127-1159. [CrossRef]

7. Meyssignac, B.; Boyer, T.; Zhao, Z.; Hakuba, M.Z.; Landerer, F.W.; Stammer, D.; Köhl, A.; Kato, S.; L’Ecuyer, T.; Ablain, M.; et al. Measuring Global Ocean Heat Content to Estimate the Earth Energy Imbalance. Front. Mar. Sci. 2019, 6. [CrossRef]

8. Le Reste, S.; Dutreuil, A.V.; André, A.X.; Thierry, V.; Renaut, B.C.; Le Traon, P.-Y.; Maze, G.; A, L. “Deep-Arvor”: A New Profiling Float to Extend the Argo Observations Down to 4000-m Depth. J. Atmos. Ocean. Technol. 2016, 33, 1039-1055. [CrossRef]

9. Bittig, H.; Maurer, T.L.; Plant, J.N.; Schmechtig, C.; Wong, A.P.S.; Claustre, H.; Trull, T.W.; Bhaskar, T.V.S.U.; Boss, E.; Dall'Olmo, G.; et al. A BGC-Argo Guide: Planning, Deployment, Data Handling and Usage. Front. Mar. Sci. 2019, 6. [CrossRef]

10. Durack, P.; Laboratory, L.L.N.; Gleckler, P.; Purkey, S.; Johnson, G.; Lyman, J.; Boywe, T. Ocean Warming: From the Surface to the Deep in Observations and Models. Oceanography 2018, 31, 41-51. [CrossRef] 
11. Zilberman, N.; King, B.; Purkey, S.; Thierry, V.; Roemmich, D. Report on the 2nd Deep Argo Implementation Workshop, Hobart, Australia, 13-15 May 2019. Available online: https://archimer.ifremer.fr/doc/00507/61873/ (accessed on 1 June 2020).

12. Roemmich, D.; Sherman, J.T.; Davis, R.E.; Grindley, K.; McClune, M.; Parker, C.J.; Black, D.N.; Zilberman, N.; Purkey, S.G.; Sutton, P.J.H.; et al. Deep SOLO: A Full-Depth Profiling Float for the Argo Program. J. Atmos. Ocean. Technol. 2019, 36, 1967-1981. [CrossRef]

13. Roemmich, D.; Alford, M.H.; Claustre, H.; Johnson, K.; King, B.A.; Moum, J.; Oke, P.; Owens, W.B.; Pouliquen, S.; Purkey, S.; et al. On the Future of Argo: A Global, Full-Depth, Multi-Disciplinary Array. Front. Mar. Sci. 2019, 6. [CrossRef]

14. Steven, J.M. The Methods of Least Squares. Mathematics Department Brown University, Providence, RI, 02912. Available online: https://web.williams.edu/Mathematics/sjmiller/public_html/BrownClasses/54/ handouts/MethodLeastSquares.pdf (accessed on 1 September 2020).

15. Schmid, C.; Molinari, R.L.; Sabina, R.; Daneshzadeh, Y.-H.; Xia, X.; Forteza, E.; Yang, H. The Real-Time Data Management System for Argo Profiling Float Observations. J. Atmos. Ocean. Technol. 2007, 24, 1608-1628. [CrossRef]

16. Fofonoff, N.P.; Millard, R.C., Jr. Algorithms for Computation of Fundamental Properties of Seawater. Unesco Technical Papers in Marine Science, Endorsed by: Unesco/SCOR/IAPSO Joint Panel on Oceanographic Tables and Standards and SCOR Working Group 51, Unesco 1983. Available online: https://pdfs.semanticscholar. org/42f5/eabc0051566f9d5b4ef469d89a505e6b0f64.pdf (accessed on 1 September 2020).

17. Underwater Acoustics: Technical Guides-Speed of Sound in Sea-Water. National Physical Laboratory, Teddington, Middlesex, UK, TW11 OLW. Available online: http://resource.npl.co.uk/acoustics/techguides/ soundpurewater/speedpw.pdf (accessed on 1 September 2020).

18. Wong, G.S.K.; Zhu, S.-M. Speed of sound in seawater as a function of salinity, temperature, and pressure. J. Acoust. Soc. Am. 1995, 97, 1732. [CrossRef]

19. Bretscher, O. Linear Algebra with Applications, 3rd ed.; Prentice Hall: Upper Saddle River, NJ, USA, 2004.

20. These Data Were Collected and Made Freely Available by the Coriolis Project and Programmes that Contribute to It. Available online: http://www.coriolis.eu.org (accessed on 1 September 2020).

21. Millero, F.J.; Li, X. Comments on "On equations for the speed of sound in seawater" J. Acoust. Soc. Am. 93, 255-275 (1993). J. Acoust. Soc. Am. 1994, 95, 2757. [CrossRef]

22. Ali, M.M.; Jain, S.; Rachandran, R. Effect of Temperature and Salinity on Sound Speed in the Central Arabian Sea. Open Ocean Eng. J. 2011, 4, 71-76.

23. Ridgway, N.M. Temperature and salinity of sea water at the ocean floor in the New Zealand region. N. Z. J. Mar. Freshw. Res. 1969, 3, 57-72. [CrossRef]

(C) 2020 by the authors. Licensee MDPI, Basel, Switzerland. This article is an open access article distributed under the terms and conditions of the Creative Commons Attribution (CC BY) license (http://creativecommons.org/licenses/by/4.0/). 